\title{
3D Printing of Interdigitated Li-Ion Microbattery Architectures
}

\author{
Ke Sun, Teng-Sing Wei, Bok Yeop Ahn, Jung Yoon Seo, Shen J. Dillon,* \\ and Jennifer A. Lewis*
}

The proliferation of microscale devices, such as micro-electromechanical systems (MEMS), ${ }^{[1]}$ biomedical sensors, ${ }^{[2,3]}$ wireless sensors ${ }^{[4]}$ and actuators ${ }^{[5]}$ drives demand for power sources with commensurate form factors. 3D microbattery designs based on micro- and nanostructured architectures ${ }^{[6-10]}$ could potentially double the energy density by fully utilizing the limited space available. To date, such architectures have been produced in planar and 3D motifs by conventional lithography ${ }^{[11-13]}$ and colloidal templating methods, ${ }^{[14]}$ respectively. Here, we print 3D Li-ion microbatteries composed of high-aspect ratio anode and cathode micro-arrays that are interdigitated on a sub-millimeter scale, which exhibit amongst the highest areal energy and power densities reported to date.

Our facile 3D printing technique allows functional inks to be precisely patterned in filamentary form over areas ranging from $100 \mathrm{~s} \mu \mathrm{m}^{2}$ to $1 \mathrm{~m}^{2}$ with minimum feature sizes as small as $1 \mu \mathrm{m} \cdot{ }^{[15-20]}$ We harness these capabilities to fabricate $3 \mathrm{D}$ interdigitated microbattery architectures (3D-IMA) composed of $\mathrm{Li}_{4} \mathrm{Ti}_{5} \mathrm{O}_{12}$ (LTO) and $\mathrm{LiFePO}_{4}$ (LFP), which serve as the anode and cathode materials, respectively (Figure 1). These active materials exhibit minimal volumetric expansion, i.e., LTO $\left(\varepsilon_{\text {linear }} \sim 0 \%\right)^{[21]}$ and LFP $\left(\varepsilon_{\text {linear }} \sim 2.2 \%\right),{ }^{[22]}$ thereby reducing the requirement for compliance in the electrode to accommodate strain that accompanies charge and discharge processes. To create 3D-IMA, we first designed and optimized concentrated cathode and anode inks. We then printed interdigitated electrodes, packaged, and electrochemically characterized these 3D Li-ion microbatteries.

To print high aspect ratio electrode architectures, the composition and rheology of each ink must be optimized to ensure reliable flow through fine deposition nozzles, promote adhesion between the printed features, and provide the structural

\footnotetext{
K. Sun, Prof. S. J. Dillon

Department of Materials Science and Engineering

University of Illinois

Urbana, IL 61801, USA

E-mail: sdillon@illinois.edu

T. S. Wei, Dr. B. Y. Ahn, Prof. J. A. Lewis

School of Engineering and Applied Sciences

Wyss Institute for Biologically Inspired Engineering

Harvard University

Cambridge, MA 02138, USA

E-mail: jalewis@seas.harvard.edu

J. Y. Seo

Department of Chemical and Biomolecular Engineering

Korea Advanced Institute of Science and Technology

Daejeon, 305-701, South Korea
}

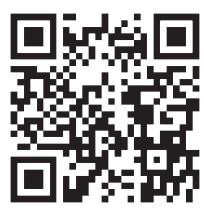

integrity needed to withstand drying and sintering without delamination or distortion. Concentrated anode and cathode inks are prepared by suspending $\mathrm{Li}_{4} \mathrm{Ti}_{5} \mathrm{O}_{12}$ (LTO, mean diameter of $50 \mathrm{~nm}$ ) and $\mathrm{LiFePO}_{4}$ (LFP, mean diameter of $180 \mathrm{~nm}$ ) nanoparticles in a solution composed of deionized water, ethylene glycol, glycerol, and cellulose-based viscosifiers via multistep process that involves particle dispersion, centrifugation, and homogenization (experimental methods). Each powder is centrifuged to remove particles above $300 \mathrm{~nm}$ in diameter to minimize ink clogging during printing. We produced LTO and LFP inks of varying solids loading and found that those with respective solids loadings of $57 \mathrm{wt} \%$ and $60 \mathrm{wt} \%$ exhibited the desired rheological and printing behavior (Figures 2a). Figure $2 \mathrm{~b}$ shows their apparent viscosity as a function of shear rate. Each ink exhibits highly shear thinning behavior with respective apparent viscosities ranging from $10^{3}-10^{4} \mathrm{~Pa} \cdot \mathrm{s}$ at $1 \mathrm{~s}^{-1}$. Figure $2 \mathrm{c}$ shows their storage modulus $\left(G^{\prime}\right)$ as a function of shear stress. The plateau modulus of each ink is $\sim 10^{6} \mathrm{~Pa}$, while their shear yield stress $\left(\tau_{\gamma}\right)$ ranges from $10^{2}-10^{3} \mathrm{~Pa}$, respectively. The magnitude of these key rheological parameters are in good agreement with those reported for other colloidal inks designed for 3D filamentary printing. ${ }^{[17-20]}$

We printed high aspect ratio, multilayer electrodes onto a glass substrate by depositing these inks through $30 \mu \mathrm{m}$ cylindrical nozzles (Figure 2d). To control ink solidification and adhesion during patterning, a graded volatility solvent system is used in which water (boiling point, b.p. $100{ }^{\circ} \mathrm{C}$ ) evaporation during printing induces partial solidification of the printed features ensuring their structural integrity, while ethylene glycol (b.p. $197.3{ }^{\circ} \mathrm{C}$ ) and glycerol (b.p. $290^{\circ} \mathrm{C}$ ) serve as humectants that promote bonding between individual layers (Figure 2e). Printed features with aspect ratios $(h / w$, where $h$ is height and $w$ is width) of $\sim 0.8$ are obtained in a single pass with a minimum width of $\sim 30 \mu \mathrm{m}$ and high-aspect ratio features are readily obtained through a layer-by-layer printing sequence (Figure 2e). The SEM images reveal that interfaces of the printed layers are well bonded to one another. Figure $2 \mathrm{f}$ shows the height and width of LTO and LFP structures as a function of the number of printed layers. Notably, their height increases linearly with layer number, while their width is nearly constant. The aspect ratios of the patterned microelectrodes range from $\sim 0.8$ to 11 for single to 16-layer high aspect ratio walls.

After printing, the dried LTO and LFP microelectrode arrays are heated to $600{ }^{\circ} \mathrm{C}$ in inert gas to remove the organic additives and promote nanoparticle sintering. Thermal gravimetric analysis (TGA) reveals that the organic species are largely removed by $\sim 300{ }^{\circ} \mathrm{C}$ (Figure S1). At higher temperatures, the LTO and LFP particles undergo initial stage sintering leading to neck

DOI: 10.1002/adma.201301036 
a)

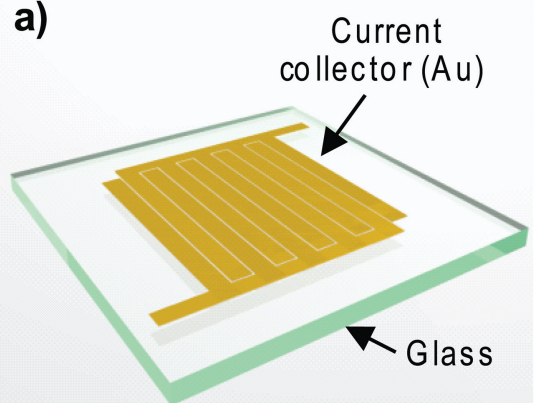

c)

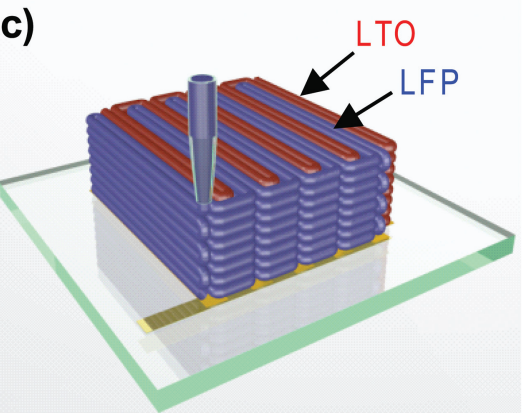

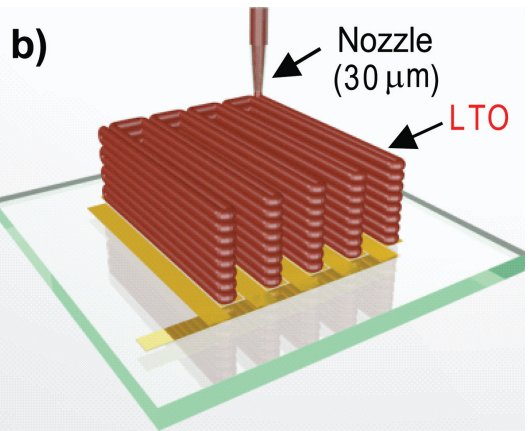

d)

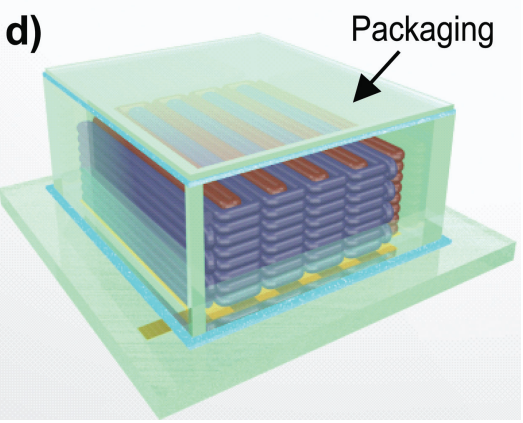

Figure 1. Schematic illustration of 3D interdigitated microbattery architectures (3D-IMA) fabricated on (a) gold current collector by printing (b) $\mathrm{Li}_{4} \mathrm{Ti}_{5} \mathrm{O}_{12}$ (LTO) and (c) $\mathrm{LiFePO}_{4}$ (LFP) inks through $30 \mu \mathrm{m}$ nozzles, followed by sintering and (d) packaging.

www.MaterialsViews.com

formation at particle-particle contacts. The annealed structures remain highly porous, which is desirable for electrolyte penetration (Figure S2). The electrical resistivities of the annealed LTO and LFP films measured by four-point probe are $2.1 \times 10^{5} \Omega \cdot \mathrm{cm}, 2.3 \times$ $10^{3} \Omega \cdot \mathrm{cm}$, respectively. These values are significantly lower than their intrinsic electrical resistivities $\left(\sim 10^{9} \Omega \cdot \mathrm{cm}\right) \cdot{ }^{[23,24]}$ We speculate that such differences may arise from residual carbon formed by decomposing the polymeric additives in an inert atmosphere (Figure S3).[25]

To investigate their electrochemical performance, we printed 8-layer and 16-layer 3D-IMA $(960 \mu \mathrm{m} \times 800 \mu \mathrm{m}$, electrode width $=60 \mu \mathrm{m}$, spacing $=50 \mu \mathrm{m})$ on glass substrates (Figure 3a) followed by drying and annealing at $600{ }^{\circ} \mathrm{C}$ for $2 \mathrm{~h}$ in an inert atmosphere (Figure $3 \mathrm{~b}$ ). The final test structures exhibited minor distortion, but no sign of shorting via contact between adjacent electrodes or delamination from the substrate. We first measured discharge properties for half-cells composed of LFP (Figure 3c) and LTO (Figure 3d) electrodes at varying C rates.
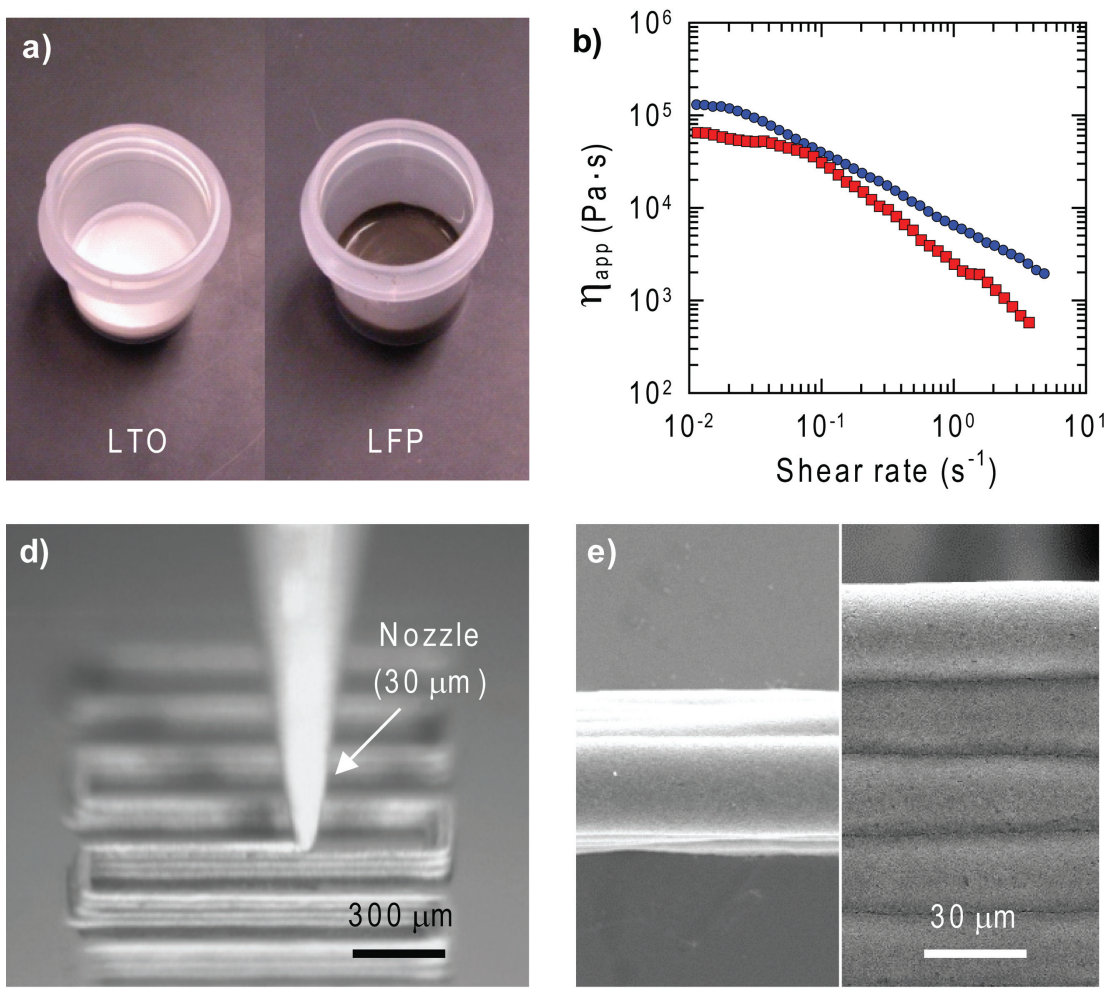

Figure 2. (a) Optical images of LTO and LFP inks. (b) Apparent ink viscosity as a function of shear rate. (c) Storage modulus as a function of shear stress for each ink. (d) Optical image of LFP ink (60 wt\% solids) deposition through a $30 \mu \mathrm{m}$ nozzle to yield multilayer structure. (e) SEM images, top (left) and side (right) views, of the printed and dried multilayer LFP structure. (f) Height and width of printed features as a function of the number of printed layers (30 $\mathrm{mm}$ nozzle diameter). [Note: Red and blue symbols correspond to data obtained on LTO and LFP inks, respectively.] 

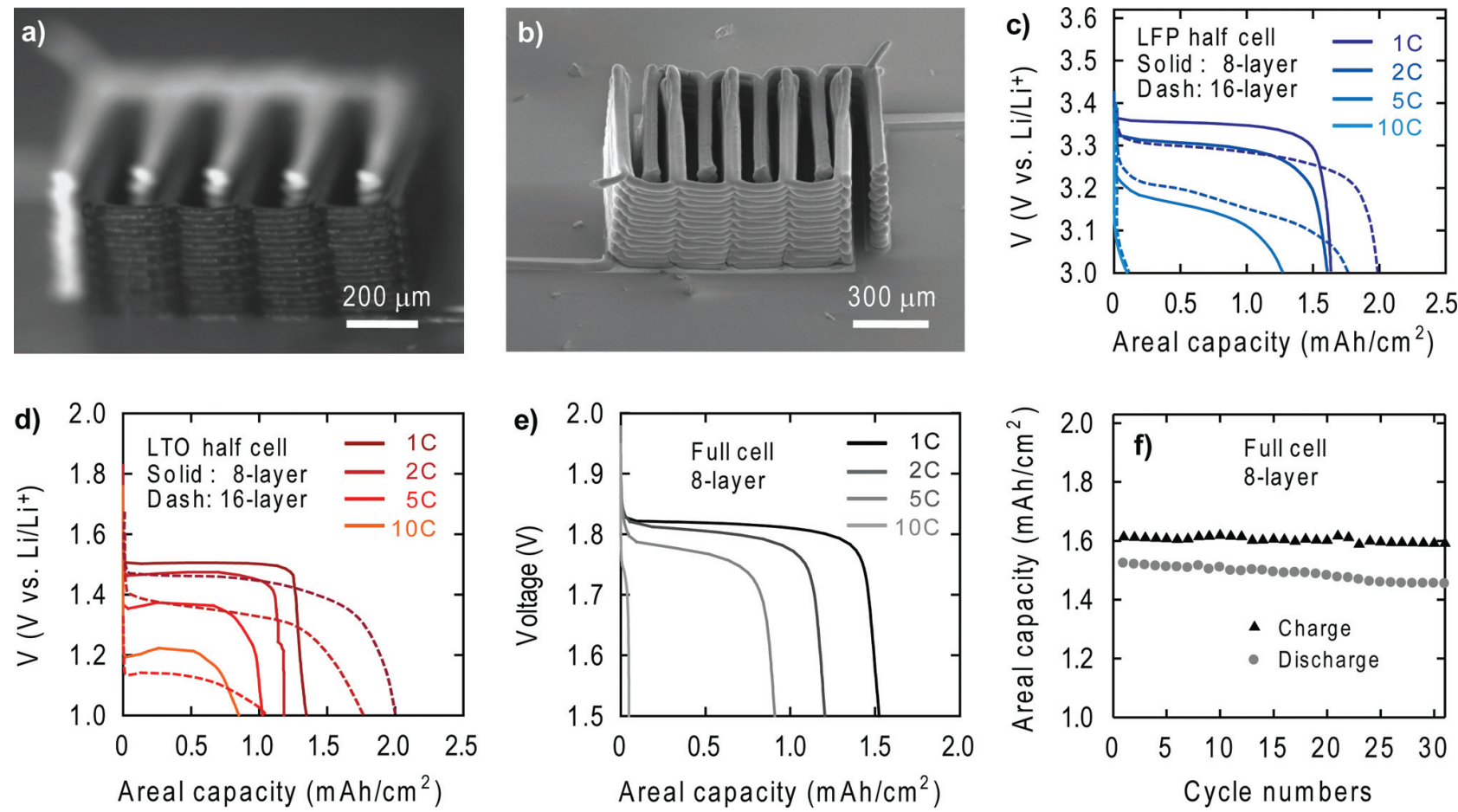

Figure 3. (a) Optical and (b) SEM images of printed and annealed 16-layer interdigitated LTO-LFP electrode architectures, respectively. Half-cell voltage as a function of areal capacity for (c) LFP and (d) LTO electrodes. (e) Full-cell voltage as a function of areal capacity for 8-layer interdigitated LTO-LFP electrodes. (f) Areal capacity of full cell composed of 8-layer interdigitated LTO-LFP electrodes measured as a function of number of cycles tested.

The specific capacities for these 8-layer structures at $1 \mathrm{C}$ are calculated to be 160 and $131 \mathrm{mAh} \mathrm{g}^{-1}$, respectively, in good agreement with their respective theoretical values of 170 and $175 \mathrm{mAh} \mathrm{g}^{-1}$. A common feature of both data is the non-monotonic variation in discharge capacity with electrode volume between the 8-layer structures and the 16-layers structures at the lowest rate $(1 \mathrm{C})$. The results indicate that the height of the structure will constrain the kinetics of the reaction. Electronic transport is the only height dependent property in the system, and likely limits the functional height of the 3D-IMA in its current incarnation. At $5 \mathrm{C}$ and $10 \mathrm{C}$, the 16-layer and 8-layer LFP electrodes exhibit the same current density of $8.33 \mathrm{~mA} \mathrm{~cm}$. The complete overlap in these data supports the hypothesis that electronic conduction limits their rate capability, as the total contribution to the capacity results from the same depletion region in both electrodes. Strategies to enhance electronic transport, e.g., through the inclusion of conductive fillers, are currently being pursued to enable higher aspect ratio 3D-IMAs.

Figure 3e depicts the areal capacity of an 8-layer LTO-LFP 3D-IMA as a function of $\mathrm{C}$ rate. The battery delivers $\sim 1.5$ $\mathrm{mAh} \mathrm{cm}^{-2}$ at a stable working voltage of $1.8 \mathrm{~V}$ when discharged below $5 \mathrm{C}$. The result corresponds well with the LFP and LTO halfcell results. Figure $3 \mathrm{f}$ demonstrates the cycle life of the 3D-IMA. Minimum decay in capacity occurs up to 30 cycles. LFP and LTO both exhibit good cycle life due to their low-strain topotactic reactions that take place at relatively low and high voltages, respectively.

Figure 4 shows a packaged 3D-IMA. A small plastic case (inner dimensions: $2.1 \mathrm{~mm} \times 2.1 \mathrm{~mm} \times 1.5 \mathrm{~mm}$ ) fabricated by


Figure 4. (a) Optical image of 3D-IMA composed of LTO-LFP electrodes after packaging. (b) Cyclic voltammetry of the packaged 3D-IMA. (c) Charge and discharge curve of the packaged 3D-IMA. 


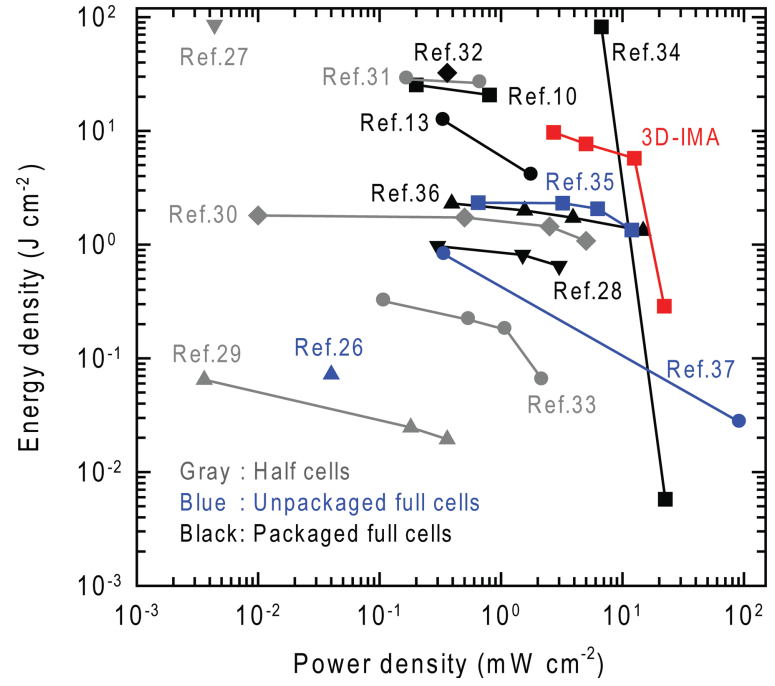

Figure 5. Comparison of the energy and power densities of our printed, unpackaged 3D interdigitated microbattery architectures (3D-IMA) to reported literature values.

laser machining contains the microbattery and liquid electrolyte (Figure 4a). The case dimensions far exceed those needed, and may be reduced by directly printing the polymeric case and liquid (or gel) electrolyte. Cyclic voltammetry performed on the packaged 3D-IMA between 1.0 and $2.5 \mathrm{~V}$ at a scan rate of $5 \mathrm{mV} \mathrm{s}^{-1}$ is shown in Figure 4b. Stable reduction and oxidation peaks occur at $1.3 \mathrm{~V}$ and $2.4 \mathrm{~V}$. After cyclic voltammetry, galvanostatic charge and discharge was conducted at a rate of $0.5 \mathrm{C}$ (Figure 4c). The capacity of the packaged 3D-IMA is $1.2 \mathrm{mAh} \mathrm{cm}{ }^{-2}$, normalized to the area of the current collector. The packaged battery does not exhibit long-term cyclability due to lack of hermeticity. Effectively packaging microbatteries $(<1$ $\mathrm{mm}^{3}$ ) that contain liquid (or gel) electrolyte is quite challenging and few examples of stable packaged microbatteries have been reported to date. ${ }^{[34]}$ Further optimization of microbattery packaging via $3 \mathrm{D}$ printing is currently under investigation.

The Ragone plot in Figure $\mathbf{5}$ compares the areal energy and power densities of our 3D-IMA with other relevant data recently reported in the literature. ${ }^{[10,13,26-37]}$ A complementary Ragone plot that compares their performance in terms of volumetric energy and power density is provided in Figure S4. We do not include data for the fully packaged 3D-IMA in either plot due to the excessively large, non-optimized package dimensions. The printed 3D-IMA compares favorably against its rechargeable counterparts in terms of both areal energy and power density. The excellent performance results from the fabrication of highaspect structures that occupy a small areal footprint, while maintaining reasonably small transport length scales to facilitate facile ion and electron transport during charging and discharging processes. While the low voltage electrochemical couple demonstrated here limits the volumetric energy density, our approach can readily be extended to other commercial lithium ion chemistries, such as $\mathrm{LiCoO}_{2}$ /graphite, to yield volumetric energy densities competitive with those reported elsewhere. ${ }^{[34,37]}$

In summary, we have printed novel 3D microbatteries composed of high-aspect ratio electrodes in interdigited architectures. Careful design of concentrated LFP and LTO viscoelastic inks enabled printing of these thin-walled anode and cathode structures. Using this LFP-LTO chemistry, we have demonstrated 3D-IMA with a high areal energy density of $9.7 \mathrm{~J} \mathrm{~cm}^{-2}$ at a power density of $2.7 \mathrm{~mW} \mathrm{~cm}{ }^{-2}$. These microbatteries may find potential application in autonomously powered microelectronics and biomedical devices.

\section{Experimental Section}

LTO and LFP Inks: LTO powder (mean diameter $=50 \mathrm{~nm}$, specific surface area $=32.6 \mathrm{~m}^{2} \cdot \mathrm{g}^{-1}$, density $=3.539 \mathrm{~g} \cdot \mathrm{cm}^{-3}$ ) was purchased from Sigma Aldrich. LFP powder (particle size $<300 \mathrm{~nm}$, density = $2.947 \mathrm{~g} \cdot \mathrm{cm}^{-3}$ ) is synthesized by a solid-state reaction, as described in detail elsewhere. ${ }^{[38]}$ Highly concentrated LTO (57 wt\% solids) and LFP (60 wt\% solids) inks are prepared by first dispersing $4.5 \mathrm{~g}$ of LTO nanoparticles in $110 \mathrm{~mL}$ of deionized (DI) water and $40 \mathrm{~mL}$ of ethylene glycol (EG, Fisher Scientific) and $3.0 \mathrm{~g}$ of LFP nanoparticles in $80 \mathrm{~mL}$ of DI water and $40 \mathrm{~mL}$ of EG. These suspensions are ball milled for $24 \mathrm{~h}$ at room temperature and then classified by a two-step centrifugation process. The suspensions are first centrifuged at $4000 \mathrm{rpm}$ for $5 \mathrm{~min}$ to eliminate large agglomerates, followed by centrifugation at $3500 \mathrm{rpm}$ for $2 \mathrm{~h}$ to collect fine particles (mean diameter of $180 \mathrm{~nm}$ ). The collected nanoparticles are re-dispersed with appropriate addition of glycerol (Fisher Scientific), 3.5 wt\% aqueous hydroxypropyl cellulose (HPC, Sigma Aldrich, $\mathrm{Mw} \sim 100,000$ ) solution, and $3 \mathrm{wt} \%$ aqueous hydroxyethyl cellulose (HEC, Sigma Aldrich) solution. The resultant homogenized LTO mixture is composed of (relative to their solids content) $27 \mathrm{wt} \%$ Glycerol, 20 30 wt\% EG, 9 wt\% HPC, 1 wt\% HEC, and DI water; whereas the LFP contained 20 wt\% glycerol, $20 \sim 30$ wt $\%$ EG, 8 wt $\%$ HPC, 2 wt\% HEC, and DI water. Through solvent evaporation at room temperature, their final solids loading (nanoparticles and cellulose) is optimized to be $55-65 \mathrm{wt} \%$. Ink rheology is measured in both shear viscometry and oscillatory modes using a controlled-stress rheometer (C-VOR, Malvern Instruments, Malvern, UK) equipped with C14 cup and bob at $25^{\circ} \mathrm{C}$ in the presence of a solvent trap to prevent evaporation. The apparent viscosity $(\eta)$ is acquired as a function of shear rate $\left(0.01-500 \mathrm{~s}^{-1}\right)$ in a logarithmically ascending series. The shear storage $(G)$ and viscous loss $\left(G^{\prime}\right)$ moduli are measured in an oscillatory mode as a function of controlled shear stress (10-10000 Pa) at a frequency of $1 \mathrm{~Hz}$ with increasing amplitude sweep.

$3 D$ printing: Before printing, interdigitated gold current collector patterns $(960 \mu \mathrm{m} \times 800 \mu \mathrm{m}$, digit width $=70 \mu \mathrm{m}$, digit spacing $=$ $50 \mu \mathrm{m})$ are patterned on glass substrates by a combination of lithographic patterning and e-beam deposition. The inks are printed using a 3-axis micropositioning stage (ABL 900010, Aerotech Inc., Pittsburgh, PA), whose motion is controlled by computer-aided design software (RoboCAD, 3D Inks, Stillwater, OK). The LFP and LTO inks are housed in separate syringes $(3 \mathrm{~mL}$ barrel, EFD Inc., East Providence, $\mathrm{RI})$, which are attached by luer-lok to a borosilicate micronozzle (30 $\mu \mathrm{m}$ in diameter produced using a P-2000 micropipette puller, Sutter Instrument Co., Novato, CA). An air-powered fluid dispenser (800 ultra dispensing system, EFD Inc.) is used to pressurize the barrel and control the ink flow rate. The typical printing speed for both LTO and LFP inks by a $30-\mu \mathrm{m}$ nozzle is $\sim 250 \mu \mathrm{m} \mathrm{s}^{-1}$ at $600 \mathrm{psi}$. After printing, the structures are annealed at $600{ }^{\circ} \mathrm{C}$ for $2 \mathrm{~h}$ in argon gas using a tube furnace. Their microstructures are characterized using SEM (Hitach S-4700). The calculated active mass of the printed LFP and LTO electrodes are 15 and $16 \mu \mathrm{g}$ per layer, respectively, based on their filament geometry and the measured solids loading of each ink.

Microbattery packaging: A thin-walled poly(methyl methacrylate) (PMMA) preform is laser cut and placed around the microbattery and sealed with PDMS gel (Sylgard 184, Dow Corning, Inc.), cured at $150^{\circ} \mathrm{C}$. The assembly is filled with liquid electrolyte and sealed with small glass cover using additional PDMS. 
Electrochemical characterization: All measurements are carried out in an argon-filled glovebox (Mbraun labstar), and electrochemical data is collected with a commercial potentiostat (SP200, Biologic Co.). For the half-cell test, the LFP and LTO electrodes are immersed in nonaqueous electrolyte $\left(1 \mathrm{M} \mathrm{LiClO}_{4}\right.$ in 1:1 ratio of ethylene carbonate:dimethyl carbonate by volume). A piece of lithium metal served as both the counter and reference electrodes. Cyclic voltammetry and galvanic charge/discharge are performed to check the electrochemical reactivity and rate capability. For the rate test, the charge rate is maintained at $\mathrm{C} / 2$, and discharge rates are varied from $1 \mathrm{C}$ to $10 \mathrm{C}$. The cycling life is also measured in constant current, and both the charge and discharge rates are fixed at $1 \mathrm{C}$. For the full cell tests in liquid electrolyte, the same tests are performed again, where LFP and LTO serve as the cathode and anode, respectively.

\section{Supporting Information}

Supporting Information is available from the Wiley Online Library or from the author.

\section{Acknowledgements}

This material is based upon work supported by the National Science Foundation under award number DMI-0749028 (K.S. and S.J.D.; powder synthesis and battery characterization) and the DOE Energy Frontier Research Center on Light-Material Interactions in Energy Conversion under grant DE-SC0001293 (B.Y.A., T.-S.W., and J.A.L., ink design, formulation and printing). J.Y.S. was supported by a Global Ph.D. Fellowship from the Korean government.

Received: March 7, 2013

Revised: May 7, 2013

Published online: June 17, 2013

[1] S. M. Spearing, Acta Mater. 2000, 48, 179

[2] C. Zhang, J. Xu, W. Ma, W. Zheng, Biotechnol. Adv. 2006, 24, 243

[3] D. A. Lavan, T. Mcguire, R. Langer, Nat. Biotechnol. 2003, 21, 1184.

[4] J. D. Fowler, M. J. Allen, V. C. Tung, Y. Yang, R. B. Kaner, B. H. Weiller, ACS Nano 2009, 3, 301

[5] P. S. Waggoner, H. G. Craighead, Lap Chip 2007, 7, 1238.

[6] J. W. Long, D. R. Rolison, Acc. Chem. Res. 2007, 40, 854.

[7] M. Armand, J.-M. Tarascon, Nature 2008, 451, 652.

[8] J. W. Long, B. Dunn, D. R. Rolison, H. S. White, Chem. Rev. 2004, 104, 4463.

[9] T. S. Arthur, D. J. Bates, N. Cirigliano, D. C. Johnson, P. Malati, J. M. Mosby, E. Perre, M. T. Rawls, A. L. Prieto, B. Dunn, MRS Bull. 2011, 36, 523.

[10] A. M. Gaikwad, G. L. Whiting, D. A. Steingart, A. C. Arias, Adv. Mater. 2011, 23, 3251.
[11] S. R. Gowda, A. L. M. Reddy, X. Zhan, P. M. Ajayan, Nano Lett. 2011, 11, 3329

[12] L. Baggetto, R. A. H. Niessen, F. Roozeboom, P. H. L. Notten, Adv Funct. Mater. 2008, 18, 1057.

[13] M. Nathan, D. Golodnitsky, V. Yufit, E. Strauss, T. Ripenbein, I. Shechtman, S. Menkin, E. Peled, J. Microelectromech. Syst. 2005, $14,879$.

[14] H. Zhang, X. Yu, P. V. Braun, Nat. Nanotechnol. 2011, , 277.

[15] J. A. Lewis, Adv. Funct. Mater. 2006, 16, 2193.

[16] J. A. Lewis, G. M. Gratson, Mater. Today 2004, 7, 32.

[17] B. Y. Ahn, E. B. Duoss, M. J. Motala, X. Guo, S.-I. Park, Y. Xiong, J. Yoon, R. G. Nuzzo, J. A. Rogers, J. A. Lewis, Science 2009, 323, 1590.

[18] J. A. Lewis, J. E. Smay, J. Stuecker, J. Cesarano III, J. Am. Ceram. Soc. 2006, 89, 3599.

[19] J. E. Smay, G. M. Gratson, R. F. Shepherd, J. Cesarano III, J. A. Lewis, Adv. Mater. 2002, 14, 1279

[20] R. B. Rao, K. L. Kracik, A. M. Morales, J. A. Lewis, Adv. Mater. 2005 17, 289.

[21] K. Zaghib, M. Armand, M. Gauthier, J. Electrochem. Soc. 1998, 145, 3135 .

[22] X. Zhang, W. Shyy, A. M. Sastry, J. Electrochem. Soc. 2007, 154, A910.

[23] S.-Y. Chung, J. T. Bloking, Y.-M. Chiang, Nat. Mater. 2002, 1, 123.

[24] J. Wolfenstine, J. L. Allen, J. Power Sources 2008, 180, 582.

[25] C. M. Julien, K. Zaghib, A. Mauger, M. Massot, A. Ait-Salah, M. Selmane, F. Gendron, J. Appl. Phys. 2006, 100, 063511.

[26] H.-S. Min, B. Y. Park, L. Taherabadi, C. Wang, Y. Yeh, R. Zaouk, M. J. Madou, B. Dunn, J. Power Sources 2008, 178, 795.

[27] M. Nishizawa, K. Mukai, S. Kuwabata, C. R. Martin, H. Yoneyama J. Electrochem. Soc. 1997, 144, 1923.

[28] M. Kotobuki, Y. Suzuki, H. Munakata, K. Kanamura, Y. Sato, K. Yamamoto, T. Yoshida, Electrochim. Acta. 2011, 56, 1023.

[29] S. K. Cheah, E. Perre, M. Rooth, M. Fondell, A. Harsta, L. Nyholm, M. Boman, T. Gustafsson, J. Lu, P. Simon, K. Edstrom, Nano Lett. 2009, 9, 3230.

[30] M. M. Shaijumon, E. Perre, B. Daffos, P.-L. Taberna, J.-M. Tarascon, P. Simon, Adv. Mater. 2010, 22, 4978.

[31] H. Mazor, D. Golodnitsky, L. Burstein, A. Gladkich, E. Peled, J. Power Sources 2012, 198, 264.

[32] H. Kim, J. Proell, R. Kohler, W. Pfleging, A. Pique, J. Laser Micro/ Nanoeng. 2012, 7, 320.

[33] S. R. Gowda, A. L. M. Reddy, X. Zhan, H. R. Jafry, P. M. Ajayan, Nano Lett. 2012, 12, 1198.

[34] W. Lai, C. K. Erdonmez, T. F. Marinis, C. K. Bjune, N. J. Dudney, F. Xu, R. Wartena, Y. M. Chiang, Adv. Mater. 2010, 22, E139.

[35] K. Yoshima, H. Munakata, K. Kanamura, J. Power Sources 2012, 208, 404.

[36] J. B. Bates, N. J. Dudney, B. Neudecker, A. Ueda, C. D. Evans, Solid State lonics 2000, 135, 33.

[37] J. H. Pikul, H. G. Zhang, J. Cho, P. V. Braun, W. P. King, Nat. Commun. 2013, 4, 1732.

[38] B. Kang, G. Ceder, Nature 2009, 458, 190 